\title{
Young Lecturers' Catalyst Technique towards Excellent Research Culture in Malaysia Scenario
}

\author{
Mohammad Syuhaimi Ab-Rahman ${ }^{1,2}$, Mohd Jailani Mohd Nor ${ }^{3}$, Ahmad Kamal Ariffin Mohd Ihsan ${ }^{3}$, Azamin \\ Zaharim $^{4} \&$ Afiq Hipni ${ }^{2}$ \\ ${ }^{1}$ Department of Electrical \& Electronical Engineering, National University of Malaysia, UKM Bangi, Malaysia \\ ${ }^{2}$ Research Advancement Strategy \& Planning (RASP), National University of Malaysia, UKM Bangi, Malaysia \\ ${ }^{3}$ Department of Mechanical and Material Engineering, National University of Malaysia, UKM Bangi, Malaysia \\ ${ }^{4}$ Center of Engineering Education, National University of Malaysia, UKM Bangi, Malaysia \\ Correspondence: Mohammad Syuhaimi Ab-Rahman, Department of Electrical and Electronical Engineering, \\ National University of Malaysia, 43600, UKM Bangi, Malaysia. E-mail: syuhaimi1977@gmail.com
}

Received: March 10, 2013 Accepted: April 16, 2013 Online Published: December 30, 2014

doi:10.5539/ass.v11n3p1 URL: http://dx.doi.org/10.5539/ass.v11n3p1

\begin{abstract}
A university's strength is very much depending on the leadership of the professors as well as the passion of young researchers. Their experience, expertise and spirit lead to the excellence of the university and as well as the reputation. There is however a certain mature period for young lecturers to make them capable of doing a quality research. The maturity denotes the readiness to conduct a proper reasearch and to carry other responsibilities in providing a platform of contribution towards the university, society and Nation. Hence, they have to be independent to utilise all resources in achieving their goals and target. This paperwork acts as a guide to expedite their maturity by providing information to ensure the continuance of the research field. The proposal of the study is based on the case study and brainstorming session through several workshop organised by research group.
\end{abstract}

Keywords: excellent culture, young researcher, research university, mentor, Excellence Catalyst Model (ECM)

\section{Introduction}

A research is defined as a process of solution finding based on the analysis and study of related factors (Sakaran, 2000). It is the prime task of an academician nowadays to conduct a research to discover new findings or knowledge meanwhile the current knowledge is developed to another level. Research and innovation must be of something meaningful and have an impact towards the society and the Nation. The findings must be resourceful and valuable which bring wealth to the Nation as well as changes in the society's quality of life. Thus, research planning has to be in accordance of the client's needs. A good research which brings an impact has to be conducted in between the economic business and social business to reduce disparities. With reference of the future technology, local scientists are believed to be able to gain the trust of the community on Malaysia's R\&D by using their abilities to acquire such technology and the competitiveness in them. Thus, it is hoped that this could bring more profit than loss in our economy.

Today, a research is no longer done as to acquire a degree scroll, but it has become a compulsory task. Thus, it is mandatory for academicians to possess good skills in conducting research. A quality and systematic research will lead to historic findings that give a huge impact on the nation's development. Education and research are two vital fields which need to be addressed to trigger the finding of new knowledge and innovative inventions parallel with good management skills. Since the task and role of a lecturer are becoming more complex along with huge responsibilities, hence, smart research methods and techniques to reduce pressure need to be exposed to them. In conjunction with that, Ministry of Higher Education Malaysia needs to provide a complete research management module to assist and guide the researchers of higher learning institutions to conduct a more effective research and most importantly to avoid stress and pressure to lecturers. The complete module should include identification of strength and available resources, as well as smart research technique such as fellow researcher, Multi-Dimensional Assessment (MDA) (Ab-Rahman, 2011), research collaboration, upgrading conference-to-journal article (C2J) \& upgrading Progress report-to-manuscript (PR2M), monitoring structures, 
monitoring pattern, periodic target, out of campus activities (Ab-Rahman \& Zalmi, 2012b). The technique to inspire young researchers consists of three main elements which are:

Element 1: Catalyst and Evident Target
1. Mentor
2. Exhibition \& Intellectual Property
3. Management
4. Community Service
5. Journal (Quality \& Quantity)
6. Reference \& H-Index

Element 2: Facilities and Alternatives

1. Research grant

2. Students Scholarship

3. Partial Laboratory \& Full Laboratory

4. Monitoring \& Nurturing

Element 3: Culture of Excellence

- Research Method

- Supervision Strategy

- Management System \& Research Strategy Planning

\section{Lecturers' Responsibilities}

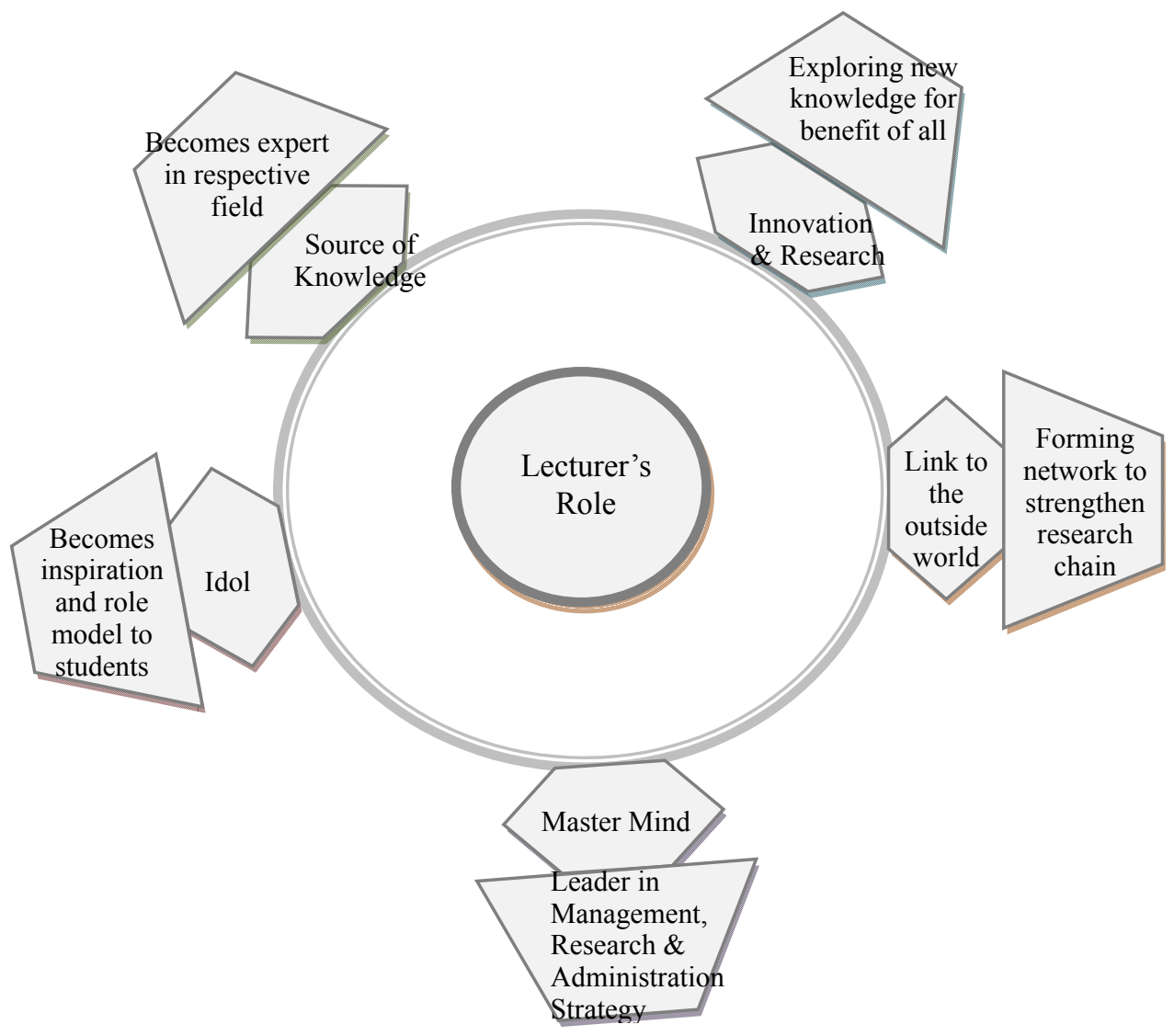

Figure 1 . The roles of lecturers, making the career prestigious and respected by the society 
As a professional, the responsibilities of a lecturer are not only confined to those of teaching and administration, but also contribution to the society should be made priority. As scholars, they serve as the masterminds and planners of social and economic activities thus enhancing the quality of life. National Development will not be attained if there is no group to plan and draw efficient strategies to achieve the set goals. Lecturers are now the bridge to the outside world through researches and teachings. This is the best and fastest platform in creating collaboration between nations. To achieve the goals of PSPTN in developing first class mentality human capital, there are many programmes, upgrading the quality of teaching and learning and innovation are instilled in the teaching curriculum which need to be revised and adjusted (Ab-Rahman et al., 2011c). Meanwhile, lecturers play the leading role in instilling this culture and come up with such reports for the purpose of accreditation and audit such as Engineering Accreditation Council (EAC), Malaysia Qualification Framework (MQF), International Organisation for Standard (ISO) and many more. The task of a lecturer is becoming more complex with higher responsibilities. Figure 1 below shows the roles of a lecturer which consist of teaching, research and community service which are divided into 5 parts of teaching, research, advisory, network, administration and reasearch and innovation.

\section{Fourteen Factors of Young Lecturers' Excellence}

\subsection{Mentor}

A mentor is just like a tattoo. It stays in the skin forever. A good mentor who gives good guidance towards excellence will always be remembered. Thus, the first thing that young lecturers/researchers need to do is to find mentors. The mentor must be of an experienced senior lecturer in the research field and he must be able and ready to guide. The mentor does not necessarily be in the same research field of the mentee. Utmost important is that he is charismatic and ready to guide. We could form a new research field and combine both ideas in research management, innovation in teaching and learning and etc. Most mentors are of a big position in administration and this would get us involved with their work routine. Indirectly, we get the opportunity to explore new knowledge and experience. The question is, are we ready yet to take challenges, criticism, new tasks and new responsibilities? The choice is in your hand. Are we complacent enough with our position for a long term period or do we want to be a young respected lecturer with higher ranking?

\subsection{Research Grant}

Financial support is the source of energy for a research. The bigger the grant, the more research can be conducted. This could produce a good quality research with better quantity. But it is not necessarily true. It could be otherwise and does not mean with a small grant, a research cannot produce a good quality research with better quantity. The utmost important thing is, to diversify the effective techniques on maximising the outcome from a grant. One of the techniques is by identifying the type of grant whether it is an operating or research grant. Each grant has different traits and in other words, the budget depends on the type of grant. Operating grant helps to improve the KPI of a research team by consenting to use the budget for journal publishing, attending workshops/conferences, organising catalyst and monitoring workshop. The outgrowth of every activity must be contributed to the university's KPI. On the other hand, research grant has a wider scope of expenses including the purchase of raw materials and assets needed for the research. Figure 2 shows the example of grants available in one of university in Malaysia and the scope of consumption.

\subsection{Research Method}

Qualitative and quantitative research consists of similar basic elements but however using different approaches. Quantitative is usually related to experimental research involving numeric data and statistics. This method is usually used for pure science research which is numerical and prototype oriented. On the other hand, qualitative is more descriptive in nature with naturalistic monitoring and a process of understanding based on general assumption. It is often used for social science research. Figure 3 shows depicted the method of research may be used in the research activities which according the focus area (discipline). In the history of science development, both aspects are interrelated and not separated, as the purpose of knowledge is to seek the truth. The separation occurs only during the development of Western science in the mid $19^{\text {th }}$ century AD where sciences are divided into categories. Mat Rofa Ismail (2004 \& 2006) who discussed the both aspects in the development philosophy of science had concluded that natural science is not science emerged as an objective in its own knowledge, but is a branch of philosophy that makes the qualitative aspects of metaphysics as a primary goal. Science should be seen as being loaded with qualitative aspect, not as mere technology products. Meanwhile, Zainal (2006) was in the opinion that the Western defined science as purely quantitative monitoring. Even though both qualitative and quantitative research plays a vital role in the development of sciences, it is ironic that scientists currently are not keen to opt for qualitative research. This syndrome simply occurs because quantitative research is said to be 
objective while qualitative is descriptive. Maximizing Revenue and creating varieties with Qualitative and Quantitative Integration.

\subsection{Students Scholarship}

Every university offers a graduate scheme in proportion and within the prescribed period. There are two types of graduate scheme, one that includes tuition fees and the other without tuition fees. Each supervisor must know the conditions and procedures to apply this scholarship as the scheme can save the research grant's allocation to be used to add the number of students or for other purposes. Various schemes are offered such as Fellowship (Prime, RU and University), Centralised Human Capital, National Science Fellowship as depicted in Figure 4.

\subsection{Partial Laboratory \& Full Laboratory}

Many researchers are dreaming of having their own research laboratory with complete facilities in order to conduct a research. Nevertheless, most researchers with their own laboratory are not able to conduct a proper research due to lack of equipment and financial support. There are even some researchers who have an equipped laboratory with advanced facilities but there is no development on the research. A laboratory, facilities and financial support are the key to success in conducting a research but that does not mean that those who lack in these factors cannot conduct a research. Sincerity and honesty are the most important elements to conduct a research.

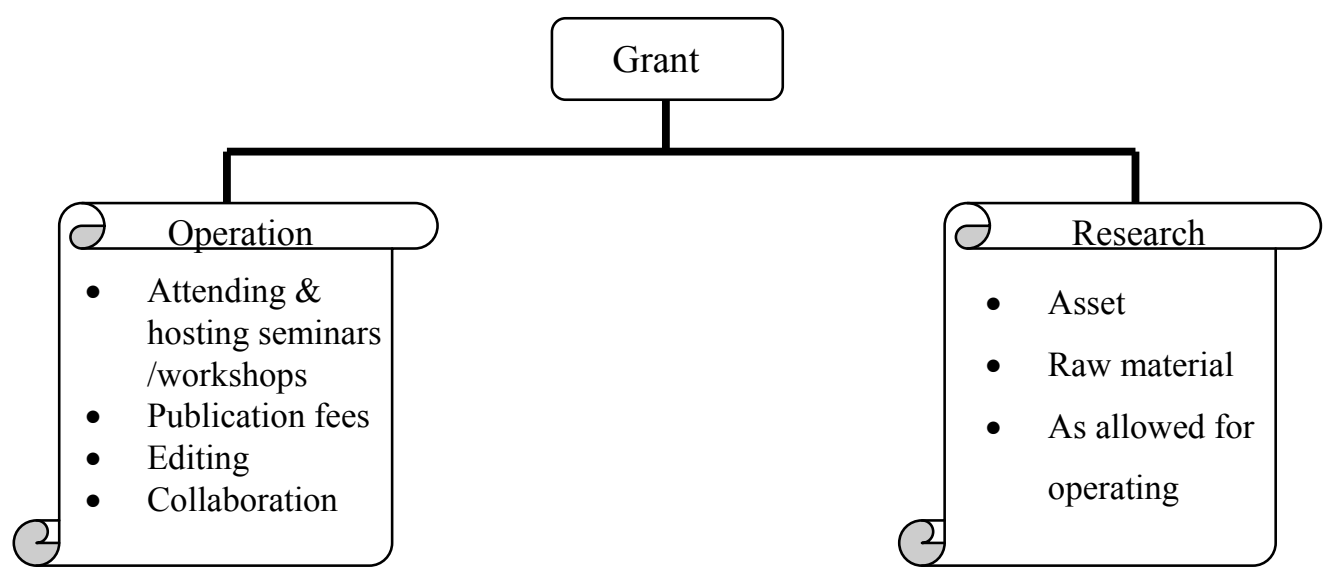

Figure 2. The roles of lecturers, making the career prestigious and respected by the society through the Two (2) research methods used which are qualitative and quantitative

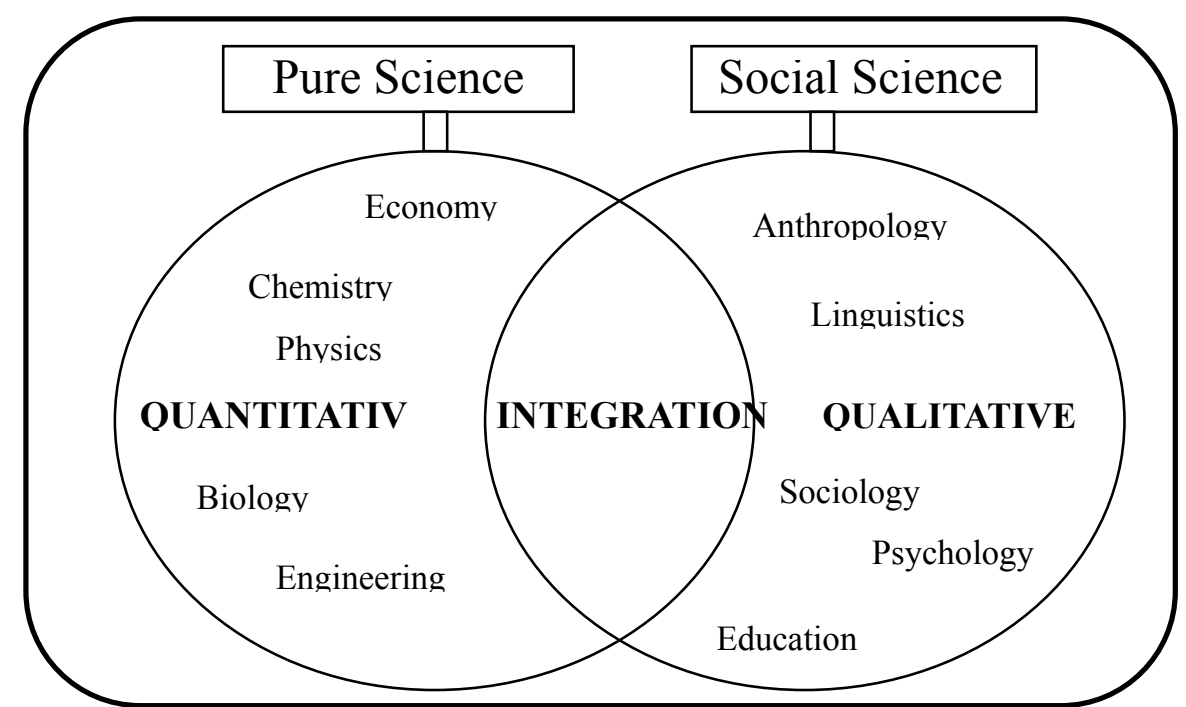

Figure 3. The integration method involves the implementation of the combination of the two approaches in a study 


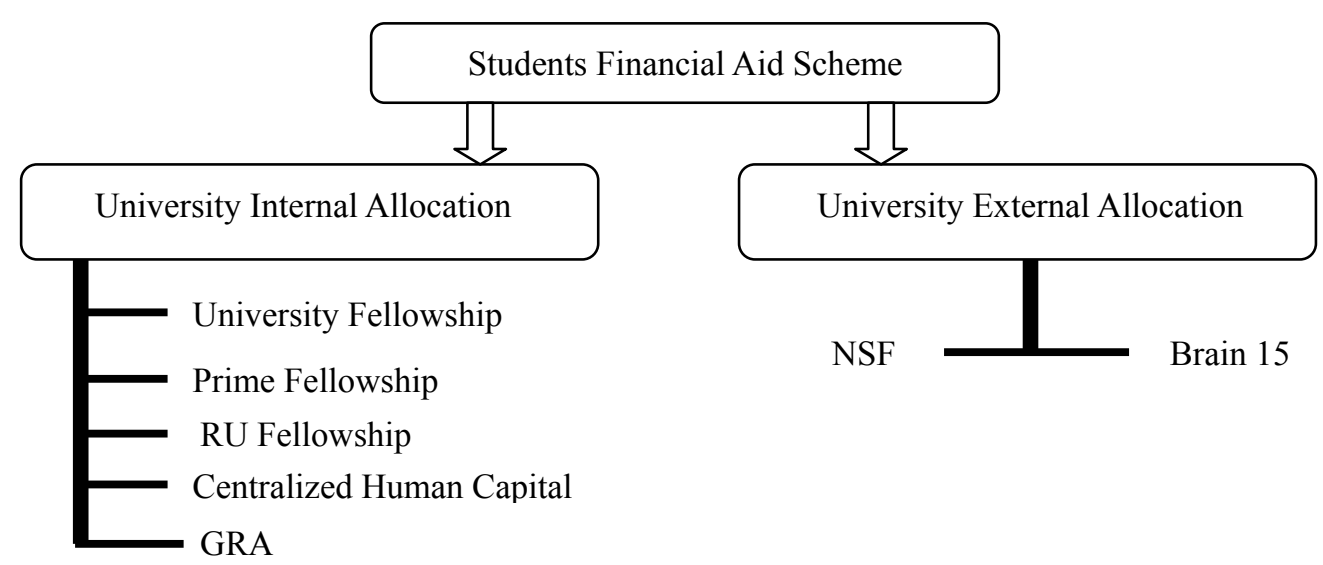

Figure 4. Two types of financial aids for students

There are even some lecturers who are willing to share rooms with research assistant to ensure good quality ideas can be generated for the research (PARTIAL LABORATORY). Some even travel miles away to facilitate other university's equipment. This is what we call as perseverance. Those with strong determination will always be able to come up with great impact results. Various research methods can be done with limited resources. As a start, they can use the simulation technique by using commercialised software to achieve the research objective. Other than that, they can also study the open source software by using analytical model. With that, when a large grant is obtained, they can start their own research empire (FULL LABORATORY). What important is that researchers must be creative and be patient in conducting a research. They should have an eagle view towards their research to gain variety of perspectives so they can creatively achieve their research objectives by using the limited resources. It would be suffice to provide a space for students to develop a partial laboratory. Perhaps a small research team consisting of few lecturers can be formed to utilise the existing meeting room, teaching laboratory or other facilities. It actually depends on our sincerity and determination regardless what type of laboratory we have.

\subsection{Supervision Strategy and Monitoring}

Monitoring is the best method to ensure the sustainability of a research. Methods that are commonly used to monitor are log book, hard copy or soft copy report as well as students' presentation. With the belief of 'all research reports can be published', monitoring method is no exception from publications. Reports submitted by the students can be revised for the purpose of producing a journal or proceeding paper if it is up to the standard and quality of a journal like what is discussed below. This part will explain the upgrading process from progress report to a journal.

Graduate students often experience problems which delay their studies or prevent them from finishing. According to Helm (1989) these problems are threefold, namely problems in the research design, the collecting and processing of information and the writing of the report. The problems could be due to inexperience of the student, to poor supervision or an inefficient system (Mouton, 2001). Rademeyer (1994), Hockey (1994) and Smith and West-Burnham (1993) found that the successful completion of a dissertation was just as much a function of the abilities of the student as of the supervisor. Numerous research findings have pointed out that there are high proportions of graduate students who fail to complete their studies within the time given. Many factors contribute to this and the major problem is related to the research and supervision process.

Monitoring structure plays a vital role in ensuring the success of a research team. It represents on how we manage the students according to their level (undergraduate and post graduate level thesis and Philosophy Doctor) and their research topics. One of the best structures is the mentor mentee system where undergraduates will be monitored by post graduates meanwhile post graduates will be monitored by philosophy doctor candidates as shown in Figure 5. As referred to Figure 5, part of the undergraduates' project will contribute to the post graduates' project and likewise, the post graduates' project will be part of the philosophy doctor candidates' thesis project. This system will save the supervisor's time which can be spared for other activities. Example of the monitoring structure is shown in the organisational monitoring structure below. A Philosophy Doctor candidate is capable of monitoring two post graduates to support his research. Each post graduate is entitled to have one undergraduate to assist and a course work post graduate. An orderly structuring will lead to a systematic and excellent research (Ab-Rahman et al., 2011b). 


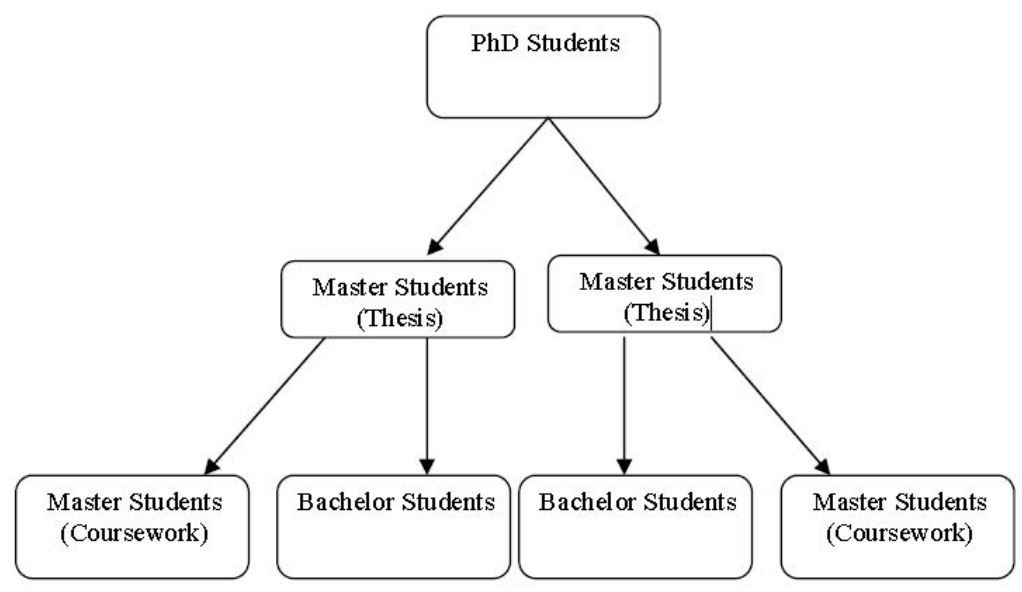

Figure 5. Effective monitoring hierarchy

\subsection{Students Monitoring}

Monitoring can be done at the level of research findings. It starts from the writing of progress reports. Each student is required to prepare a research report within a particular period and supervisors will monitor the research progress reports prepared. The progress reports can also be planned and developed into research results in the form of proceedings and journal articles, such as; Introduction, related Literature Review, Comparative analysis, Methodology, results, critical analysis, discussion and references. Once the manuscript is upgraded, it may be sent for evaluation by any of your areas of focus and thrust. Do not be upset if it was still rejected. Restart with evaluating and analysing the comments and criticism. Figure 6 shows the plan of manuscript writing towards producing proceeding and journal article. The process is interrelated and distinguishable based on the scope, breadth, depth of the analysis made.

a. Monitoring the Research Results

This is also essential to ensure that the students are on the right path in their research. Weekly brief meeting, monthly progress presentation or discussion can be done to achieve this objective. It is advisable to have a standardised log book or report form for students to fill in to show what they have done so far. If the progress is as stated in the schedule, perhaps students can be motivated to pursue more in their findings. If it is lacking, supervisors not need to be worried because this is normal in the world of research. Different point of views are needed, perhaps from other experts to figure out what should be done next.

\section{b. Monitoring by the students and Research Results}

There are various ways used to monitor the students' development and the research results to get a well planned research results. While students manage to complete their studies within the stipulated period and at the same time being active in producing researches, it is a good example in producing journal articles. Students are exposed with planning chapters for thesis writing and the probabilities of research results (examples of articles) to be published. For instance, Chapter 1 and Chapter 2 are the leading studies where statement of issue is introduced apart from literature studies and comparative analysis. Thus, a 'Review Article' can be prepared align with Chapter 1 and Chapter 2. Table 1 represents a planning table as a reference for the students to produce journal articles based on their chapters in thesis writing. The journal article then will be presented together with the chapters in their thesis. If this strategy is being used, it is expected that at least 3 articles can be produced in every research. Table 2 shows the example of a journal publishing planning table for students as a guideline to motivate them to publish.

Table 1. Identification of appropriate journal articles written is also important in ensuring production targets are achieved

\begin{tabular}{ll|l}
\hline Types of Article & Suggested Journal \\
\hline Proposal (New Ideas, Research Method) & Journal A & Journal B \\
Review & Journal C & $\begin{array}{l}\text { The quality of publishing improving } \\
\text { when the research progress towards the } \\
\text { end/completing. }\end{array}$ \\
Research (Proof of Concept) & Journal D & \\
\hline
\end{tabular}




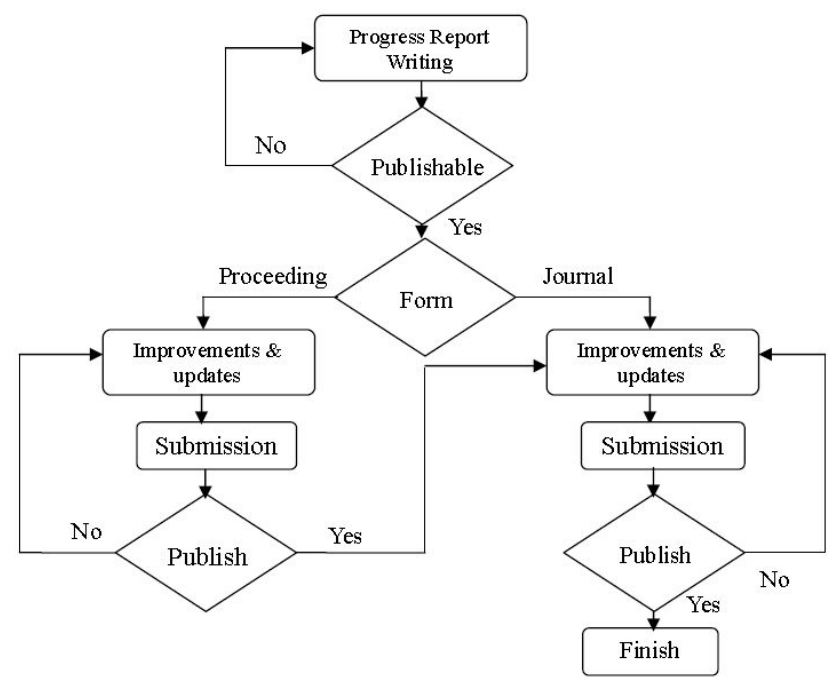

Figure 6. Progress report improvements and journal fund conversion plan

Table 2. Example of a potential journal publishing planning table

\begin{tabular}{lclc}
\hline \multicolumn{1}{c}{ Chapter } & Article Type & Potential Submitted Journal & Impact Factor (2013) \\
\hline Chapter 1 \& Chapter 2: & \multirow{2}{*}{ Review Article } & Optical Review & 0.542 \\
& & Optical Fiber Technology & 1.188 \\
& & Optics Communication & 1.542 \\
\hline Chapter 3: & Art of Design/ & Optica Applicata & 0.542 \\
Methodology & Methodology & Opto-Electronics Review & 1.279 \\
\hline \multirow{3}{*}{ Chapter 4: } & \multirow{2}{*}{ Analytical } & European Physical Journal - Applied Physic & 0.71 \\
Analytical & & Optical and Quantum Electronics & 1.078 \\
& & Journal of Modern Optics & 1.169 \\
Chapter 5: & Journal of Quantum Electronics & 2.113 \\
Simulation & \multirow{2}{*}{ Simulation } & Optica Applicata & 0.542 \\
& & OPTIK & 0.769 \\
\hline Chapter 6: & \multirow{2}{*}{ Experimental } & IET Communication & 0.72 \\
& & Optical Engineering & 0.958 \\
\hline & & ETRI Journal & 0.41 \\
& & Journal of Network and System Management & 0.438 \\
Chapter 7: & \multirow{2}{*}{ One Completed } & Journal of Optical Communications and & 1.547 \\
Result \& Discussion & \multirow{2}{*}{ Research Article } & Networking & 1.806 \\
& & Journal of Optical Society of America B & 2.176 \\
& & Photonic Technology Letters & 2.259 \\
\hline
\end{tabular}

\subsection{Journal (Quality \& Quantity)}

The impact assessment factor is very much affecting the H-Index value. This is because approximately $100 \%$ Journals listed in Q1 and Q2 are from a particular field and all journals in this group have high assessment factor. Therefore, if the H-Index value is to be increased, it is encouraged to publish a focussed journal. The higher the assessment impact, the higher the probability of our journal to be mentioned and reviewed. Other than that is to increase the H-Index value. Now, bonuses like reward system or promotion of group and individual assessment are based on the H-Index and it has become compulsory for a researcher to always monitor their H-Index value (Ab-Rahman \& Zalmi, 2012a ).

There are 2 steps to increase the value of h-Index. Firstly, by publishing high quantity of journals. Thus, the likelihood for our journal to be mentioned in any journals is high. To increase the quantity of annual research, it is best to refer to this for good techniques. High quantity publishing is essential as researches will have to refer and mention their published articles at the same time. Self references are also counted in increasing the value of 
index-H. Secondly, is to conduct a research to date than the previous research. This is because those articles have high possibilities to be referred by the future researchers. The research results are usually published in the journals under the Q1 group. Few tips can be used to publish journals under Q1 and Q2. Figure 7 shows the components or efforts can be made to increase the H-Index value.

In a nutshell, this Index is used as self-assessment and to assess the goals while the impact factor indicates the target to be achieved.

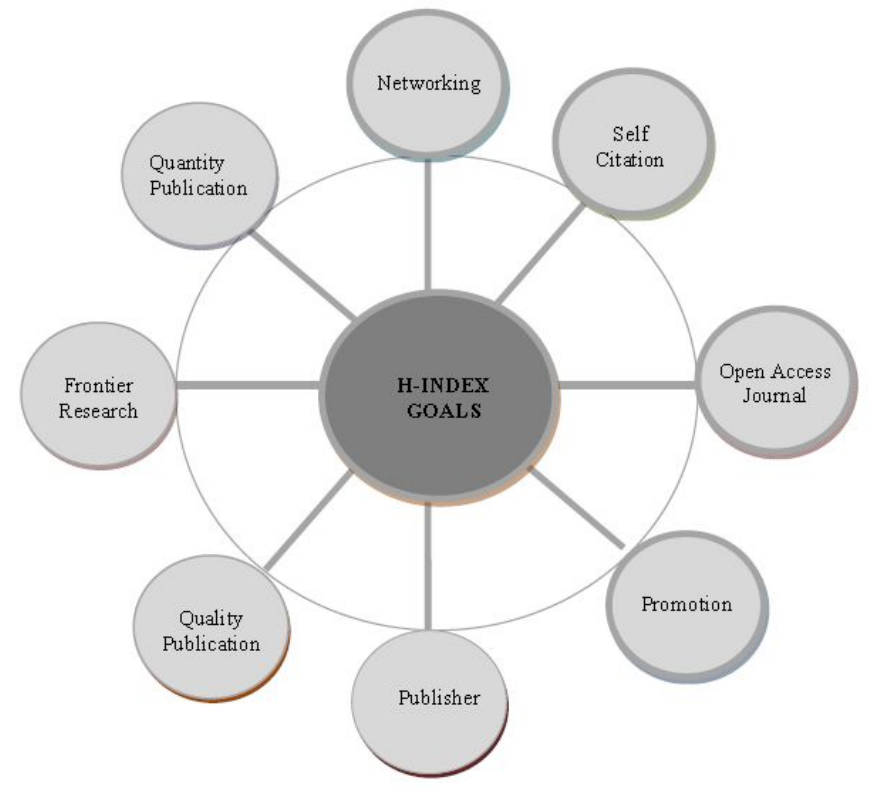

Figure 7. Components that contribute to the increase of H-Index value

\subsection{Exhibition \& Intellectual Property}

Participating exhibitions is one of the initiatives to encourage the students to be more focussed towards research works. Efforts will be doubled up by participating exhibition and competition. As a result, the research work will be expedited within a short period. Thus, the filing process of patent application will be easier with the existence of prototypes along with research reports. Then the products can be commercialised. Apart from that, this will also helps researchers to seek for research grant to assist them in upgrading and finishing the research end result. Figure 8 explains the benefit gain from the exhibition and intellectual property.

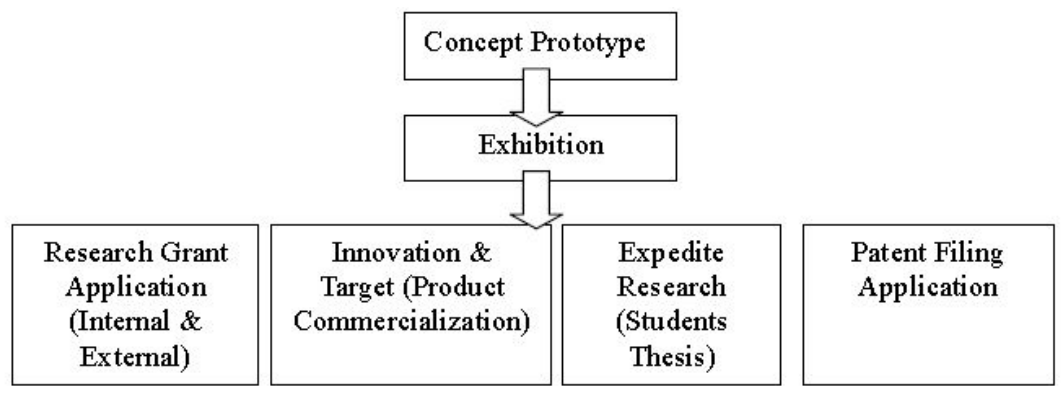

Figure 8. Benefits from hosting exhibition

\subsection{Administration}

A research has shown, those who involve in the administration of a university are those who contribute most of the university's KPI. Logically speaking, it is true that those who appreciate even a single minute will make full use of the time to get their work done. These people who are wise in managing their time will always have a strategy to fully utilise their free time with something beneficial. Congratulations to them! This is distinguished with those who have more free time but always opt to procrastinate believing that they still have plenty of times. 
As a result, they failed to get the work done within time frame thus contribute nothing to the university. Try and have a look, these types of people are always around us.

\subsection{Monitoring \& Nurturing}

During promotion interview, maturity is the utmost essential element demanded. The general presumption is that, maturity will come through time. The more experience, the more mature a researcher gets. The question is, how to erase the stigma that young researchers are mostly not matured enough? We will get the answer by monitoring the students as well as the young lecturers in terms of their teamwork in ensuring the success of a research. Hence maturity can be evaluated along the way. Meanwhile, 'Nurturing' is essential in measuring maturity of a person in a particular field.

\subsection{Community Service}

With the existence of a research team, all the planned activities can be held successfully. Other than that, the research laboratory can also be used as an activity planning centre which involves the society. Figure 9 shows on how a motivational workshop is held for school children on Science and Engineering.
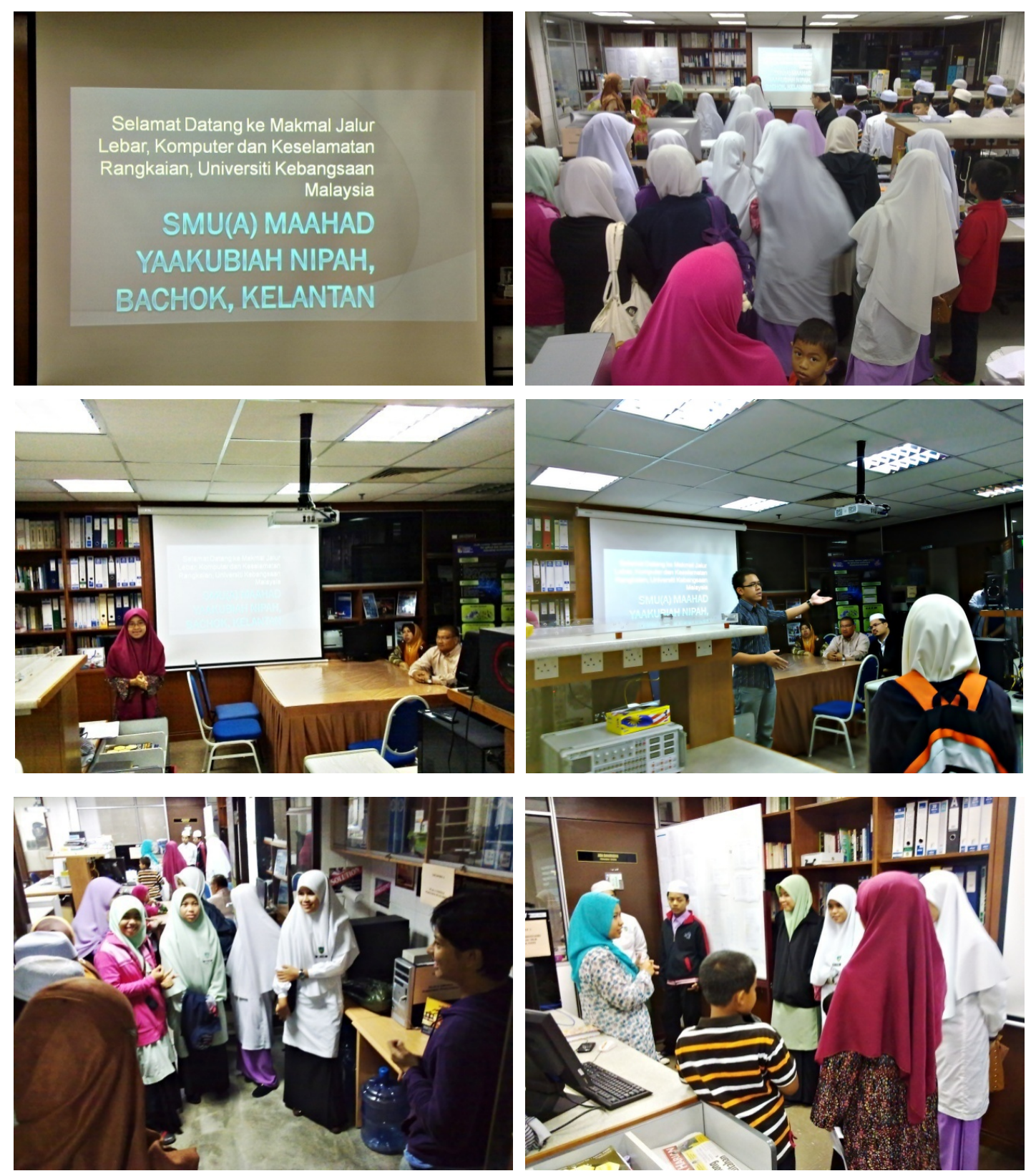

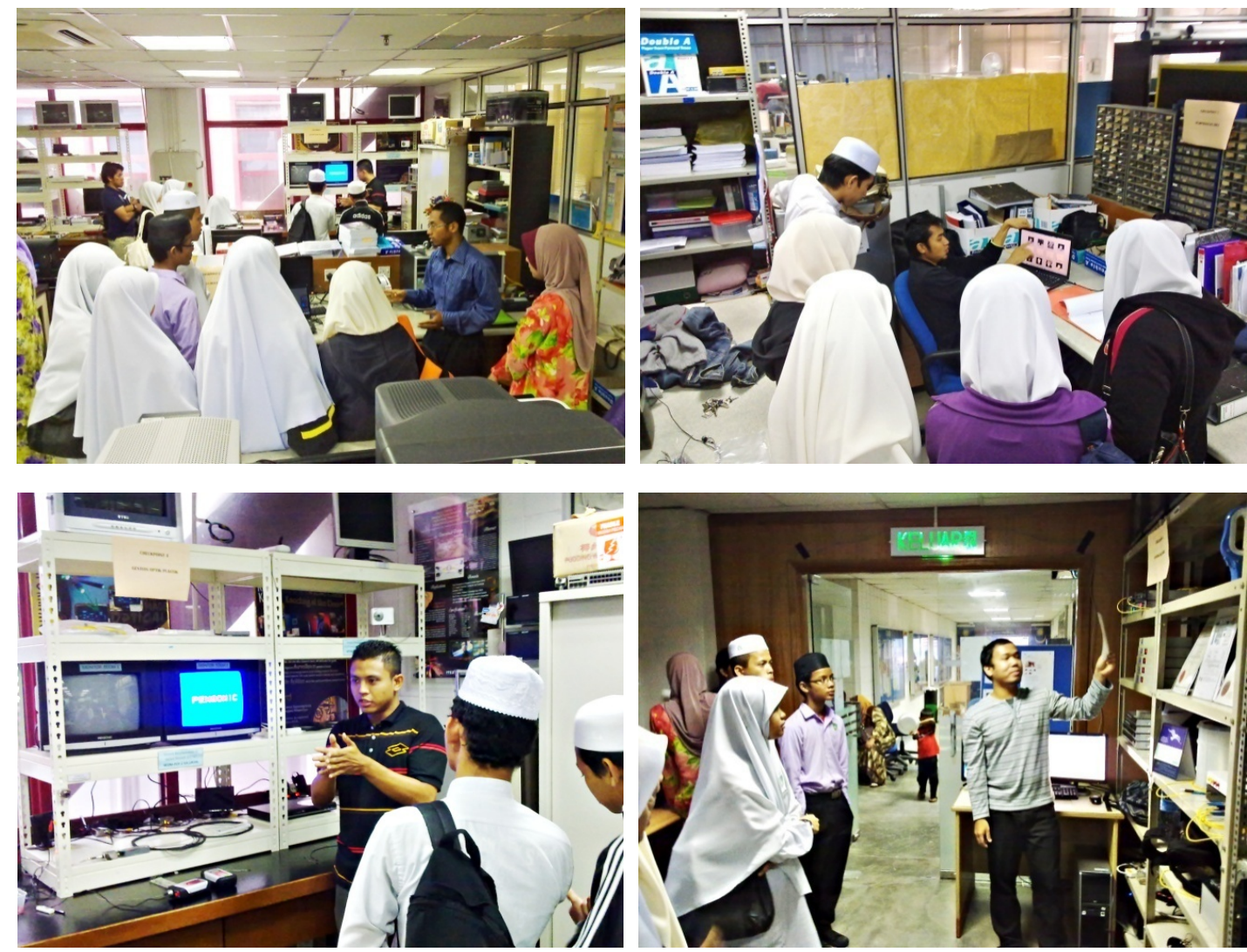

Figure 9. A series of pictures for a community service (school trip to one of the laboratories in a high-ranking local university)

\subsection{Reference and H-Index}

The actual parameter in determining a quality of a research is the reference. It comes in three main forms namely; Total Reference (TR), H-Index and Impact Factor (IF). The purpose of evaluating articles to published papers is to assess the publications and the research produced. The best article will bring influence to other universities' research. Total Reference gives the total frequency of the articles of the researchers, the department, the university or the State mentioned on a cumulative basis. Impact factor refers to the measurement of the frequency of an article in a journal been mentioned in a particular period/a given year. The ratio is calculated by reference to the number of articles published. Publishing Quantity (KNP) and Publishing Quality (KLP) was the instrument used to increase the reference value while there is some other way, through their own publications as well as a good collaboration.

\subsection{Management System \& Research Planning Strategy}

Publications generation system consists of four (4) groups; Information and Data Generation Division, Review and Correction Division, Development Division and the Division of Management and Monitoring. Flow chart for the development and expansion of a journal manuscript is shown in Figure 10.

1. Information and Data Generation Division: The most important part in research which leads to the production of required data and information. The bigger the division, the more journal manuscripts will be developed. Composed of students and research assistants who conduct the research.

2. Review and Correction Division: Completed journal manuscript requires reading by second party, third party and so on to ensure the effectiveness of information delivered. This includes the use of sentences and grammar in particular manuscript which is written in English. There are many options that can be used to review and edit manuscripts, which some are payable (e.g. Americanjournalexpert.com, Supaproofread.com). On the internet, many agencies, companies or institutes are offering the editing and revising services of manuscripts-whether journals or books. Usually the cost for a manuscript is up to RM1,000. For researchers who do not have a large grant may use the services of young tutors or lecturers to carry out the process. It depends on whether the researcher would like to include their name as co-editor of the service or pay the service using the reward earned later. Do not be too proud not to include their names in your research as this is the most effective 
way to attract young researchers to work together for future research. This is what we called 'Nurturing the youngers' which is also categorized as your contribution in educating and developing young researchers to do research. It gives a big impact on your research for the department/faculty branding.

c. Development Division: Previous division requires the services of young researchers (young lecturers and tutors as the editor(s) of the completed manuscript was. Meanwhile Development Division requires the expertise of senior lecturers (e.g. Professor) to expand the research result. The results will be reviewed different in dimension / perspectives allowing more analysis to be done so that the current research will keep on going with added value. Multi Dimensional Assessment (MDA), which will be discussed in the Mohammad Syuhami ab-Rahman 2011, can be done to maximize the results from previous research.

d. Division of Management and Monitoring: This division refers to the main task of the researchers as supervisors to manage the developed journal manuscripts. It can also be assisted by research assistants who involve in the project management. Apart from being involved in the process of submitting manuscripts for further development, this section also serves to ensure that all parts of the above run successfully Ab-Rahman et al., 2011a).

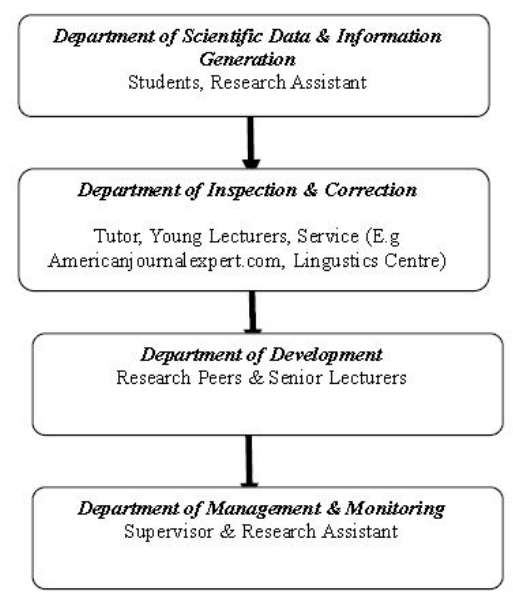

Figure 10. Division of department for improved journal publication strategy

Unpolished Article (Just Come the Oven)

\section{TIER1 Publication Make Over Platform}

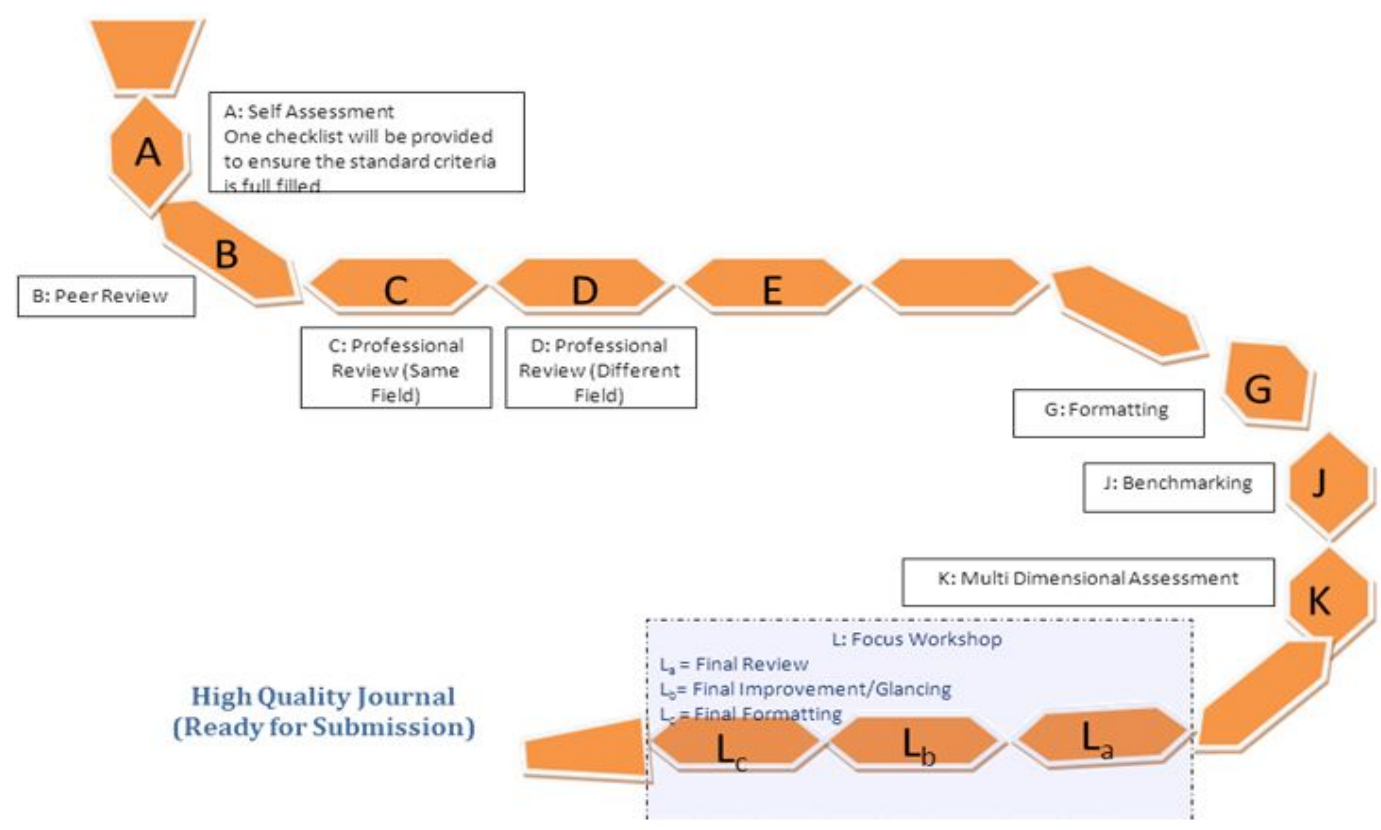

Figure 11. Platforms and steps in creating tier 1 articles 

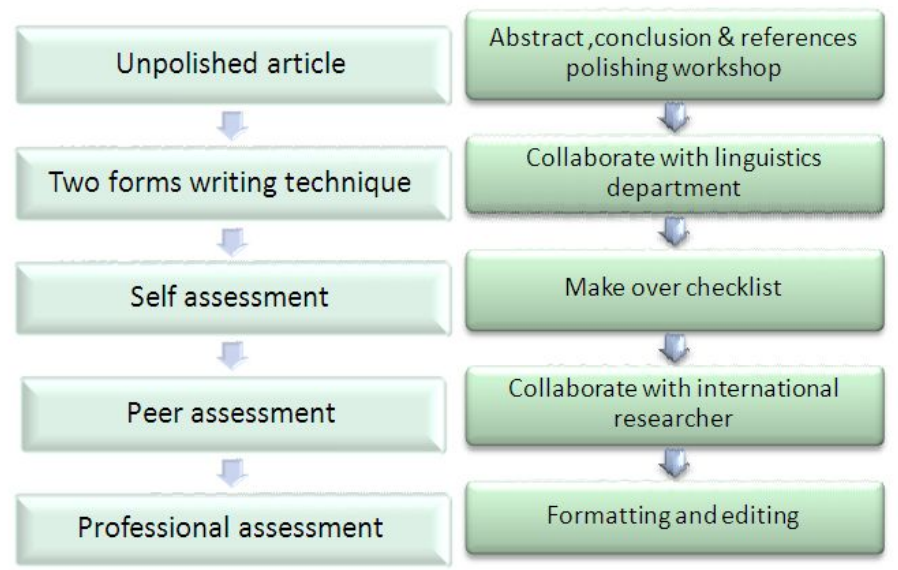

Figure 12. Step-by-step technique to upgrade article

The examples of manuscript revision are shown in Figure 11 and Figure 12. Figure 11 explain the serial process of manuscript improvement where in Figure 12 the two type of manuscript version have been produced in one time (parallel). The structure of the process flow can be made through discussion amongst the fellow researcher and the availability of the components and support from the research institute. However the complexity and number of section is proportional to the quality of the manuscript produced from the process.

\section{Summary}

This paper lists some of the catalyst to the excellence of researchers which consist of the universities' academic staff. Management strategy in doing research is an important element to offset the growing burden of lecturers. Apart from an efficient strategy, other supporting factors are also important in ensuring that the research foundation and direction is in the right path. This paper describes the components that need to be taken by young lecturers to excel in their career as a lecturer cum researcher. A clear direction is needed so that efficient strategies can be developed to reach the destination. The formation of Research Empire is a good initiative to identify strength so that the lecturers will not be outdated in doing research work. Supports from the system developed by each university are also important in moulding the spirit towards the interpretation of research. Figure 12 shows the Excellence Catalyst Model (ECM) that emphasizes on innovation and creativity that can be applied in grooming young lecturers. The three main cores that initiate the excellence in four area (teaching, research, management and community) are through the practising of excellence research culture, catalyst activities and efficient techniques.

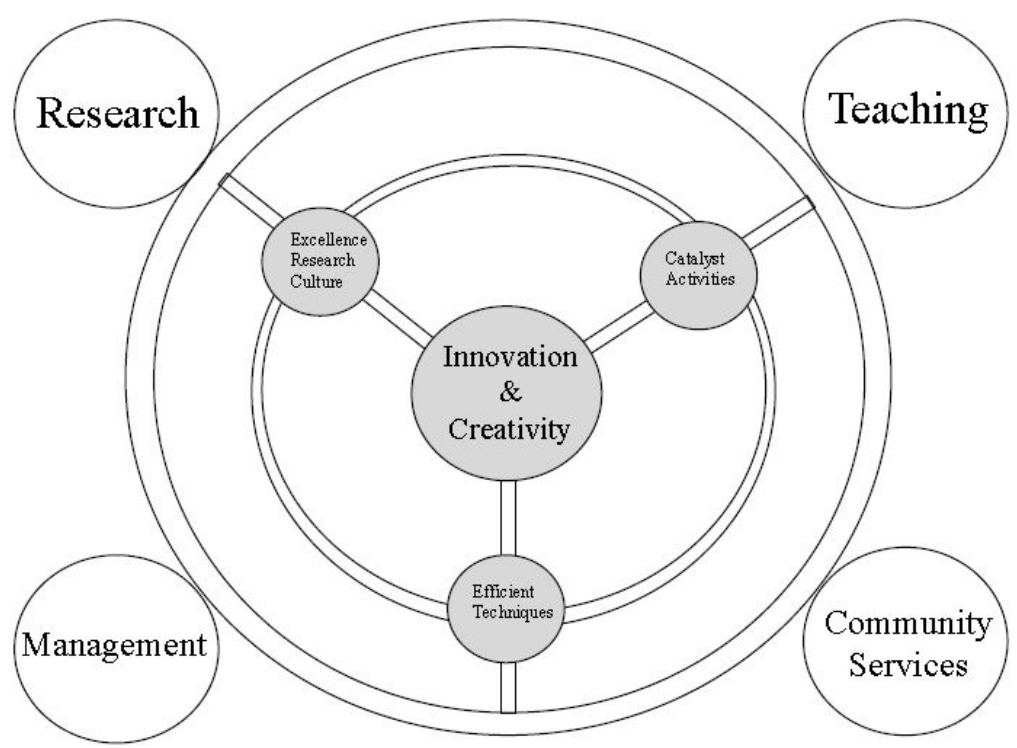

Figure 13. Excellence Catalyst Model that emphasizes on innovation and creativity 


\section{References}

Ab-Rahman, M. S. (2011). Multi-Dimensional Assessment (MDA): Setting the Research Diversity. Journal of Engineering and Applied Sciences, 6(6), 452-456.

Ab-Rahman, M. S., \& Zalmi, S. (2012a). Research Quality and Publication Quality: An Important Parameter. Journal of Engineering and Applied Sciences, 7, 39-44. http://dx.doi.org/10.3923/jeasci.2012.39.44

Ab-Rahman, M. S., \& Zalmi, S. (2012b). Workshop of Publishing Stimulation: A Method of Increasing the Quantity. Journal of Engineering and Applied Sciences, 7, 31-38. http://dx.doi.org/10.3923/jeasci.2012.31. 38

Ab-Rahman, M. S., Md Zain, S., Hipni, A., Mohd Nor, M. J., Ihsan, A. K. A. M., Ramli, N. F. L., ... Razak, N. H. A. (2011a). High Quality Students by Improving Research Supervision. The Sosial Sciences, 6(5), 344-349.

Ab-Rahman, M. S., Md Zain, S., Hipni, A., Mohd Nor, M. J., Ihsan, A. K. A. M., Ramli, N. F. L., ... Razak, N. H. A. (2011b). Effective Supervision Strategies in Improving the Quality and Quantity of Research. International Business Management, 6(5), 312-318.

Ab-Rahman, M. S., Md Zain, S., Hipni, A., Mohd Nor, M. J., Ihsan, A. K. A. M., Ramli, N. F. L., ... Razak, N. H. A. (2011c). Introduction to Research, Sub-Breaking and Ethics: The First Knowledge Before Starting The Empire. The Social Sciences, 6(5), 386-390.

Helm, C. A. G. (1989). Maatreels om die probleme van nagraadse navorsingstudente te verminder - ' $n$ literatuurstudie. Suid-Afrikaanse Tydskrif vir Hoeer Onderwys, 3(2), 79-85.

Hockey, J. (1996). Strategies and Tactics in the Supervision of UK Social Science PhD Students. Qualitative Studies in Education, 9(4), 481-500. http://dx.doi.org/10.1080/0951839960090409

Ismail, A., Abiddin, N. Z., \& Hassan, A. (2011). Improving the Development of Postgraduates' Research and Supervision. International Education Studies, 78-89.

Ismail, M. R. (2004). Matematik Merentas Tamadun. Kuala Lumpur: Dewan Bahasa Dan Pustaka.

Ismail, M. R. (2006). Falsafah Sains: Pendekatan Kualitatif. Kuala Lumpur: Dewan Bahasa Dan Pustaka.

Mouton, J. (2001). How to Succeed in your Master's and Doctoral Studies. Pretoria: Van Schaik.

Rademeyer, G. (1994). Thesis supervision: Getting the genie out of the lamp. South African Journal of Higher Education, 8(2), 92-95.

Sakaran, U. (2000). Research Method for Business: A Skill Building Approach (3rd ed.). Singapore: John Wiley $\&$ Sons.

Smith, P., \& West-Burnham, J. (1993). Mentoring in the Effective School. Essex: Redwood Books.

Zainal, B. (2006). Peluang-peluang Penyelidikan Kualitatif. Dalam Ilmu Falak. Retrieved from http://www.al-azim.com/masjid/seminar/falak2006/5.pdf

\section{Copyrights}

Copyright for this article is retained by the author(s), with first publication rights granted to the journal.

This is an open-access article distributed under the terms and conditions of the Creative Commons Attribution license (http://creativecommons.org/licenses/by/3.0/). 